\title{
Soil-transmitted helminths and plasmodium falciparum malaria among individuals living in different agroecosystems in two rural communities in the mount Cameroon area: a cross-sectional study
}

\author{
Irene Ule Ngole Sumbele ${ }^{1 *}$, Gladys Belanka Nkemnji ${ }^{1}$ and Helen Kuokuo Kimbi ${ }^{1,2}$
}

\begin{abstract}
Background: Soil-transmitted helminths (STHs) and Plasmodium falciparum infections remain public health problems in Cameroon. A cross-sectional study was carried out in the Mount Cameroon area to determine the prevalence and intensity of STHs and P. falciparum infections in individuals living in different agroecosystems; to assess the influence of these infections on haematological parameters; and to identify the risk factors associated with STH infections.

Methods: STH and malaria parasites were detected using the Kato-Katz method and Giemsa staining of blood films, respectively. Complete blood count values were obtained using an automatic haematology analyser. Soil samples were analysed using the sucrose floatation sedimentation method. Categorical and continuous variables were compared as required and logistic regression models were used to assess the risk factors for STH infections and anaemia.

Results: Of the 450 participants examined, STHs, P. falciparum and mixed co-infections were detected in 14.0, 33.3 and $5.6 \%$ of participants, respectively. Significantly higher prevalences of Ascaris (18.8\%) and Trichuris (7.9\%) infections were observed in participants from tea plantation areas compared to those from banana and palm plantation areas, with similar trends in egg density. P. falciparum prevalence and parasite density were comparable between the different agroecosystems. The overall prevalence of anaemia was $64.2 \%$. The prevalence of haematological manifestations such as moderate (48.0\%) and severe (8.0\%) anaemia, leucopenia (26.9\%) and microcytosis (30.8\%) was significantly higher among Plasmodium-STH co-infected participants. Soil samples from plantations showed the highest prevalences of STH eggs compared to soil samples from areas around pit toilets and public water taps. Living in a tea plantation area $(O R=3.07)$, age $(A O R=1.49)$ and lack of access to potable water $(O R=2.25)$ were identified as risk factors for STH infections, while the age groups $15-25$ years $(O R=2.928)$ and 26-35 years $(O R=2.832)$, and being female $(O R=2.671)$ were significant risk factors for anaemia.

Conclusions: STHs, malaria and anaemia are still of public health concern in plantation communities. Co-infections negatively influence haematological parameters. The tea farming agroecosystem, age and lack of access to potable water were identified as significant risk factors for STH infections.

(Continued on next page)
\end{abstract}

\footnotetext{
* Correspondence: sumbelei@yahoo.co.uk

'Department of Zoology and Animal Physiology, University of Buea, Buea,

Cameroon

Full list of author information is available at the end of the article
} 
(Continued from previous page)

Trial registration: Not applicable.

Keywords: Soil-transmitted helminths, Plasmodium falciparum malaria, Co-infection, Anaemia, Agroecosystem, Haematological values, Environmental contamination, Cameroon

\section{Multilingual abstract}

Please see Additional file 1 for translations of abstract into six official working languages of the United Nations.

\section{Background}

Soil-transmitted helminth (STH) and Plasmodium infections remain a major health problem in many developing countries. Although STH infections are relatively preventable and easy to treat, some rural areas in Cameroon still record high prevalences of these infections $[1,2]$. Closely associated with STH infections is malaria parasitaemia, with Plasmodium falciparum as the main species [3]. Malaria remains the primary reason for consultation in health facilities in Cameroon; it is responsible for $31 \%$ of consultations, $44 \%$ of hospitalisations as well as $18 \%$ of deaths occurring in health facilities in the country. In children below 5 years of age, $41 \%$ of deaths are due to malaria [4].

Several studies have shown that STH infections and malaria have remained endemic in many parts of the tropical world [5, 6] due to poverty [7], socio-economic problems and behavioural attributes [8]. Environmental factors such as the presence of bushes, stagnant water, poor sanitation, rainfall, low altitude and high temperatures may favour the growth and transmission of malaria parasites $[9,10]$. Whilst farming represents an important livelihood strategy for a considerable number of rural and semiurban dwellers, agricultural activities have also been associated with the transmission of both malaria parasites and STHs, especially hookworms [11, 12]. Previous studies have also shown that malaria-helminth co-infection patterns vary between different agroecosystems [13], hence the need to further investigate these co-infections in different agro-ecological settings. The lack of epidemiological data on STH and Plasmodium infections in rural farming communities hinders the development of informed policy on an already marginalised population.

Co-infections with STH and malaria may have considerable health consequences with controversial outcomes. While some studies have shown that helminths have a protective role $[14,15]$ others have associated helminth infections with adverse clinical outcomes in patients with malaria [16]. Although malaria and helminth infections are known etiological factors in tropical anaemia $[17,18]$, the extent to which their combined presence might interact to enhance the risk of other haematological abnormalities merits further investigation.
Previous studies in the Mount Cameroon area on malaria and helminth co-infection shave reported on their influence on the occurrence of anaemia, as well as the effect of altitude and urbanisation in children below 14 years of age $[3,19,20]$. The situation regarding older children, other age groups and farming communities in the area is unknown.

The government of Cameroon through the Ministry of Public Health has enhanced control measures against malaria and helminth infections. Such measures include the free distribution of long-lasting insecticide treated nets to all age groups, as well as free treatment of malaria among children below 5 years of age and the annual distribution of anthelmintics in primary schools since 2007 [21]. Following the intensification of control measures, more studies on polyparasitism in vulnerable populations are necessary to evaluate the impact of control efforts and to provide relevant information for policy-making.

Taking this into account, the present study was undertaken: to determine the prevalence and intensity of STHs and P. falciparum infections in individuals working in different agroecosystems in the Mount Cameroon area; to assess the influence of these infections on haematological parameters; and to identify the risk factors associated with STH infections. The findings of this study, especially for the group that is not targeted for control such as school-aged children not enrolled in schools and individuals older than 14 years of age, will provide valuable data to assist in the planning of control strategies in the country.

\section{Methods}

\section{Study sites and participants}

This study was carried out in two rural farming communities in the villages of Ekona and Tole in Fako Division, South West Region. Both farming areas are situated in the Mount Cameroon area and have different agroecosystems, as shown in Fig. 1.

Mount Cameroon is a forested area, some of which has been cleared and replaced with banana, rubber, tea and palm plantations owned by the Cameroon Development Corporation (CDC) and small independent farm holdings. Banana and palm tree plantations are located in the southern part of the area, while tea plantations are located in the western part. The banana plantation is irrigated by the use of sprinklers and could be described as an environment of swampy flat land traversed by 


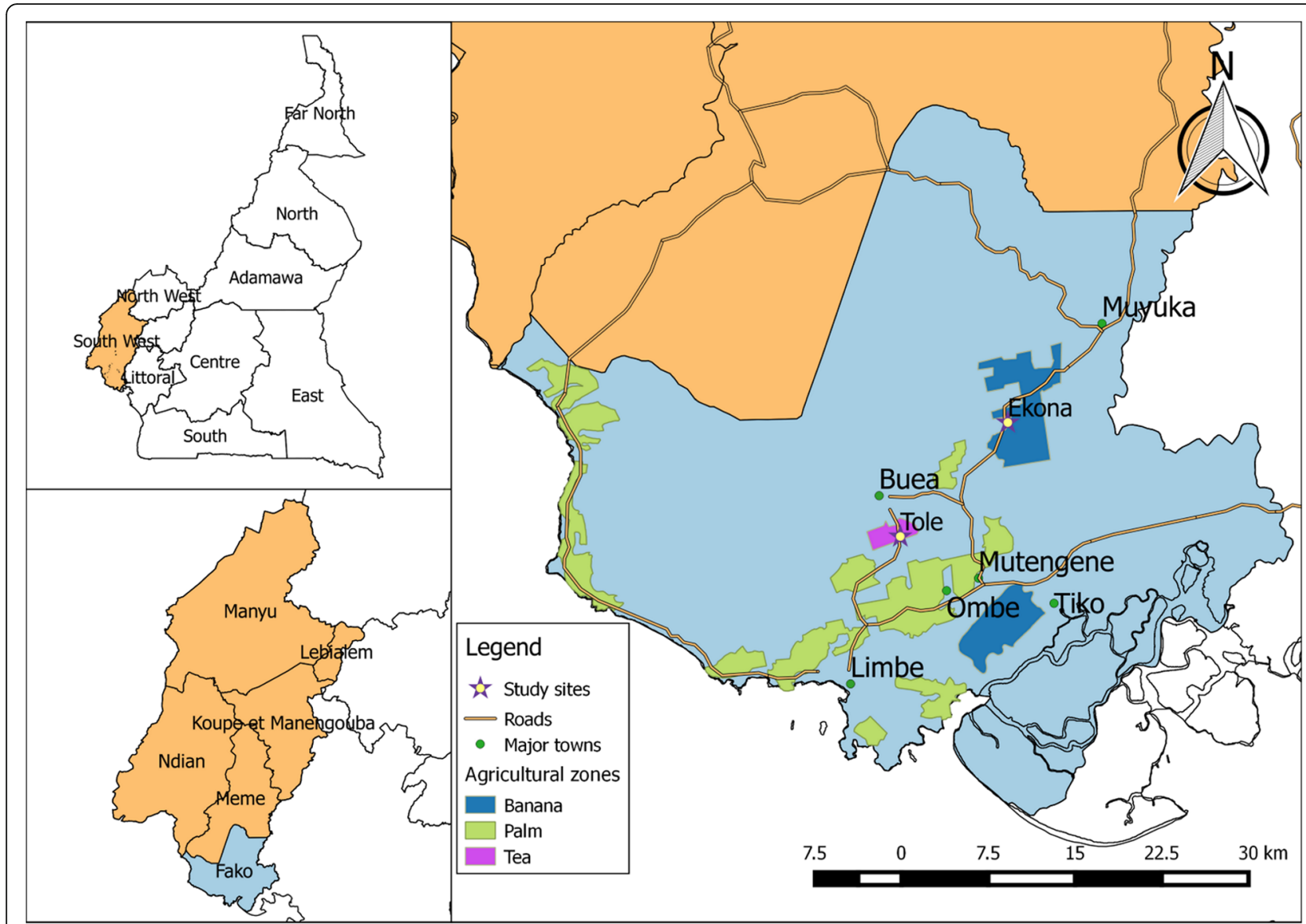

Fig. 1 Map showing the location of the study areas in Fako Division, South West Region, Cameroon

pools of irrigated water. The palm plantation is not irrigated and characterised by dense shade with little sunlight penetration. Tea plantations are characterised by short grass and shrubs that provide a wide range of pasture for livestock grazing.

The area's climate is tropical, with temperatures ranging from $18{ }^{\circ} \mathrm{C}$ to $35{ }^{\circ} \mathrm{C}$, and an average annual rainfall of about $4000 \mathrm{~mm}$ [22]. Both Ekona and Tole have two distinct seasons: a cold rainy season from March to October, and a warm dry season with frequent light showers from November to February. The majority of inhabitants in the two villages are involved in farming, trading or livestock keeping. They are of poor socioeconomic status, live in camp houses made of wood with holes and crevices, and have inadequate faecal disposal systems.

The study participants included individuals who farm, live and work in banana, palm or tea plantations. Members of their families who live in the workers' camp with them between the ages of four and 60 years were eligible to take part in the study. Only individuals who willingly accepted to participate after being explained the purpose and protocol of the study, provided written or verbal informed consent (for adults) or assent (for minors), and have lived in the village for at least the past year were enrolled in the study.

\section{Study design}

This cross-sectional study was carried out during the peak malaria transmission season between January and August 2014. The investigations entailed the use of a pre-tested, semi-structured questionnaire, measurement of body temperature using a clinical thermometer, and collection of blood, stool and soil samples for laboratory analyses. Due to a lack of information on exact population size of farmers in the different plantations, the sample size was calculated using the prevalence of $P$. falciparum malaria and helminth infections of a previous study: 64.2 and 38.3\%, respectively, in the Mount Cameroon area [3]. The sample size was determined using the formula $n=Z^{2} \mathrm{pq} / \mathrm{d}^{2}$ [23], where $n$ represented the sample size required; $\mathrm{Z}$ was 1.96 , which is the standard normal deviate (for a 95\% confidence interval, $C I$ ); $\mathrm{p}$ was $38.3 \%$, the proportion of helminth prevalence; q was $1-p$, the proportion of helminth negative; and $d$ was 0.05 , the acceptable error willing to be committed. 
The optimum sample size was estimated to be 363 . Considering a possible loss of samples due to blood clotting and non-consent to participating, the sample size was adjusted by $5 \%$ to a minimum of 381 . A total of 485 eligible participants drawn by the lottery method using the monthly pay list of farmers working in the banana (140), palm (165) and tea (180) plantations were invited together with their children to take part in the study. Potential participants were contacted through the payroll officer on payday, and the research team and community health workers scheduled a day to explain the study's purpose and protocol to the participants. Following this, potential participants were informed that a maximum of two persons, a parent and a school-aged child, would be recruited per family. The different localities for the daily collection of samples in the community centre hall were determined by the research team comprising a qualified clinician, a nurse and laboratory technicians. A total of 450 individuals consented to participate in the study, with a dropout rate of $7.2 \%$.

Each individual's body temperature was measured and individuals with a body temperature $\geq 37.5{ }^{\circ} \mathrm{C}$ were considered febrile. Parasitological and haematological analyses were performed on the blood samples collected to determine the presence of malaria parasites and to evaluate the blood elements. Collected stool samples were examined to determine the prevalence of STHs, while soil samples were examined to evaluate the environmental contamination with eggs or STH larvae in order to identify transmission hotspots.

\section{Questionnaire}

Information on agricultural land use patterns, including crop types, storage and use of water in households and on agricultural plots was obtained from the participants using a pre-tested, semi-structured questionnaire. The questionnaire also elucidated participants' socio-demographic information (age, sex, education level); use of malaria and helminth preventive measures (mosquito bed net use and wearing of shoes); pre-treatment of malaria and helminths; household conditions (block or plank house, floor type) and sanitation facilities (toilet facilities, access to potable water); and knowledge of and attitudes towards malaria and helminth infection transmission and control.

\section{Collection of blood, stool and soil samples}

Approximately $4 \mathrm{ml}$ of venous blood was collected from each consenting individual into sterile disposable syringes. Drops of whole blood were dispensed immediately on slides for the preparation of thick and thin blood films for the detection and speciation of malaria parasites, as described by Cheesbrough [24]. The remaining blood was dispensed into labelled ethylenediamine tetra-acetate tubes and placed in a cool box for transportation.
Clean, labelled, airtight plastic containers were given to each participant to return with a fresh midday stool sample. A single stool sample was collected from each participant.

Soil samples were collected within a 5-m radius of randomly selected anthropogenic activity sites in the community such as pit toilets, public water taps and yards of homes (surroundings), as well as the different plantations. Ten grams of topsoil was collected using a spoon to a depth of about $2 \mathrm{~cm}$. The samples were collected in the morning and preserved in plastic bags. All collected samples were transported to the University of Buea Malaria Research Laboratory for analysis.

\section{Laboratory procedures}

The air-dried thin blood film was fixed in 75\% methanol, and both thick and thin blood films were stained using $10 \%$ Giemsa solution [24]. Slides were then microscopically examined for the presence of malaria parasites by two independent parasitologists, and in the case of any disparity they were read by a third parasitologist. Slides were considered positive when asexual forms and/or gametocytes of any Plasmodium species were observed on the blood film. Parasite density per $\mu \mathrm{L}$ of blood was determined on the basis of number of parasites per 200 leukocytes on thick blood film with reference to participants' white blood cell (WBC) counts [24].

Asymptomatic malaria parasitaemia (AMP) was defined as the presence of Plasmodium parasites with an axillary temperature of $<37.5{ }^{\circ} \mathrm{C}$, while clinical malaria parasitaemia (CMP) was defined as the presence of any species of Plasmodium together with an axillary temperature of $\geq$ $37.5^{\circ} \mathrm{C}$ or reported fever in the previous $48 \mathrm{~h}$, or headache or joint pain.

Full blood count was performed using a URIT-3300 Automated Hematology Analyzer (Guilin Botest Medical Electronic Co. Ltd, PR China), following the manufacturer's instructions. Data on WBC, red blood cell (RBC) and platelet counts were obtained, as well as haemoglobin $(\mathrm{Hb})$ level, haematocrit (Hct), mean corpuscular volume (MCV), mean corpuscular $\mathrm{Hb}$ and mean corpuscular $\mathrm{Hb}$ concentration. Individuals were considered anaemic when $\mathrm{Hb}$ concentration fell below the World Health Organization (WHO) reference values for age or gender [25]. Anaemia was classified as either mild (between $10.0 \mathrm{~g} / \mathrm{dL}$ and the level in the WHO reference values for age or gender), moderate $(7.0-10.0 \mathrm{~g} / \mathrm{dL})$ or severe $(<7 \mathrm{~g} / \mathrm{dL})$ [24]. Leucopenia was defined as $\mathrm{WBC}<4.5 \times 10^{9} / \mathrm{L}$, microcytosis as $\mathrm{MCV}$ less than73 $\mathrm{fl}$ [26] and thrombocytopenia was defined as platelet count $<150000 / \mu \mathrm{L}$.

Stool smears were prepared and examined using the Kato-Katz thick smear method, as described by Cheesbrough [24]. Duplicate smears were prepared 
for each specimen. Each slide was allowed to clear for $30 \mathrm{~min}$, and then examined at $100 \times$ total magnification within one hour of preparation to avoid missing hookworm eggs. Morphological identifications of eggs of $A$. lumbricoides, T. trichiura and hookworm were based on identification aids, as described by Cheesbrough [24]. All the eggs in the $41.7 \mathrm{mg}$ of stool were counted and multiplied by 24 to calculate the number of eggs per gram of faeces (epg). As a quality control measure, all positive slides and $10 \%$ of randomly selected negative smears were re-examined by a third experienced parasitologist who had no knowledge of the previous results. An average of the counts was utilised. For the STH species ( $A$. lumbricoides and T. trichiura), the following egg count classifications were used to determine infection intensity: for A. lumbricoides infection, light $=1-4999 \mathrm{epg}$, moderate = 5 000-9 999 epg and heavy = $\geq 10000$ epg; while for $T$. trichiura, light $=1-999 \mathrm{epg}$, moderate $=1$ 000-9 999 epg and heavy = $\geq 10000$ epg [27].

Approximately $2 \mathrm{~g}$ of sieved soil samples were analysed using the sucrose floatation sedimentation method, as described by Kagei [28]. For each soil sample, two independent analyses were performed, and if either of the two revealed eggs, then the sample was considered contaminated. STH eggs were identified with reference to the identification aids, as described by Cheesbrough [24].

\section{Statistical analysis}

Analysis of the data was done using the IBM Statistical Package for Social Sciences (IBM SPSS Inc., Chicago, IL, USA) version 19. Data were summarised as means and standard deviations (SDs), and percentages were used in the evaluation of the descriptive statistics. Proportions were compared using the chi-square test $\left(\chi^{2}\right)$. Nonparametric tests such as Kruskal-Wallis test and MannWhitney $U$ test were used to compare geometric mean egg density (GMED) of STHs across the different agroecosystems, sex and age groups (4-14, 15-25, 26-35, 3645 and $\geq 46$ years), as well as variations in mean haematological indices ( $\mathrm{Hb}, \mathrm{Hct}, \mathrm{RBC}, \mathrm{WBC}$ and platelet) with infection category where appropriate. Geometric mean parasite density (GMPD) of P. falciparum infections across the different agroecosystems and sex were compared using ANOVA and the Student's $t$-test, respectively. Geometric means for STH eggs and P. falciparum counts were computed for those positive only and the log transformed STH eggs and P. falciparum counts were used in the analysis. Exploratory analyses were performed to select and prioritise variables to be entered into binary and nominal regression models. Any potential factor that had at least a modest $(P<0.2)$ relation with the outcome variable was included in the regression models. Binomial logistic regression (backward stepwise) models were run with the presence of any helminth as the outcome variable. In addition, nominal regression models were run with $\mathrm{Hb}$ concentration below the WHO reference values for age or gender as outcome variables to determine the risk factors for anaemia. All results were measured at $95 \%$ CIs and were considered to be significant at $P<0.05$.

\section{Results \\ Baseline characteristics}

Out of the 485 eligible participants, a total of 450 $(92.8 \%)$ individuals within the age range of 4-60 years (median age $=25.5$ years) gave their consent or assent, and provided both faecal and blood samples for the evaluation of STH and P. falciparum infections, as well as haematological parameters. Of the 450 participants, 165 were tea plantation workers from Tole, while 127 were banana plantation workers and 158 were palm plantation workers from Ekona. The proportions of males $(49.6 \%)$ and females $(50.4 \%)$ in the study population were similar. A greater proportion of the participants belonged to the 4-14 years age group (37.6\%) and the least belonged to the $\geq 46$ years age group (9.1\%), as shown in Table 1.

Overall, the prevalence of STH infections in the studied population was $14.0 \%(C I=11.1-17.5 \%)$. Individuals were infected with one of two species of STHs: Ascaris lumbricoides $(12.0 \%, C I=9.3-15.3 \%)$ and Trichuris trichiura (4.2\%, CI =2.7-6.5\%); no hookworm infections were detected. Out of the 63 individuals with STH infections, 54 (85.7\%, $C I=75.0-92.3 \%)$ were infected with $A$. lumbricoides. The overall prevalence rates of light, moderate and heavy Ascaris infections were 87.0\% (CI = 75.6-93.6\%), $11.1 \%(C I=5.2-22.2 \%)$ and $1.9 \%(C I=0.3-$ 9.8\%), respectively. All Trichuris infections were light.

P. falciparum $(33.3 \%, C I=29.1-37.8 \%)$ was the only species of malaria parasite detected. Fever occurred in $34.2 \%(C I=30.0-38.7 \%)$ of the participants, anaemia in $64.2 \%(C I=59.7-68.5 \%)$ and $C M P$ in $15.3 \%(C I=12.3-$ 19.0\%) (see Table 1).

Mixed STH and $P$. falciparum co-infections were detected in $5.6 \%(C I=3.8-8.1 \%)$ of the participants. The prevalences of Ascaris, Trichuris and Ascaris plus Trichuris were comparable in individuals with $P$. falciparum (13.3, 4.7 and $16.7 \%$, respectively) and those without (11.7, 4.0 and $12.7 \%$, respectively). Although not significant $(P=0.62)$, the GMED per gram of faeces of Ascaris was higher in malaria-negative individuals (1 522, range $=96-10$ 800) than malaria-positive individuals ( 1 187, range $=72-9600$ ). In contrast, the GMED of Trichuris was higher in malaria-positive individuals (196, range $=48-1200)$ than in malaria-negative individuals $(112$, range $=24-960)$. Overall, the GMED per gram of faeces for individuals with STHs was higher 





among malaria-negative ( 1325 , range $=48-760)$ than malaria-positive individuals $(909$, range $=72-9600)$.

\section{Influence of the agroecosystem}

As shown in Table 1, the prevalence of STHs was significantly higher in participants from the tea plantation area (21.2\%, CI $=15.7-28.1 \%)$ compared to the banana and palm plantation areas. Significantly higher prevalences of A. lumbricoides $(18.8 \%, C I=13.6-25.4 \%)$ and $T$. trichiura $(7.9 \%, C I=4.7-13.0 \%)$ were observed in the tea growing community as compared to the other agroecosystem communities. No significant differences were observed between agroecosystems and infection loads. Only one participant from the tea plantation area had a heavy infection (3.2\%, CI $=0.6-16.2 \%)$.

For $P$. falciparum, the prevalence and densities were comparable in participants from the different agroecosystems. However, AMP prevalence was significantly higher in participants from the palm plantation area (25.3\%, $C I=19.2-32.6 \%)$ as compared to those from the tea plantation $(14.5 \%, C I=10.0-20.7 \%)$ and banana plantation $(13.4 \%, C I=8.5-20.4 \%)$ areas. No significant differences were observed between the prevalence of anaemia and different agroecosystems (see Table 1).

\section{Effects of sex and age}

STH infection prevalence and intensities were higher in females than in males. However, only the difference in prevalence of $T$. trichiura in females $(6.2 \%, C I=3.7-$ $10.1 \%)$ and males $(2.2 \%, C I=1.0-5.1 \%)$ was statistically significant. No significant differences between age and prevalence of STHs were observed. Nonetheless, the prevalence of any STH was highest in participants of the $\geq 46$ years age group than in their counterparts (see Table 1).

P. falciparum infection prevalence was comparable in males and females, however, it was significantly higher in participants aged $4-14$ years $(47.3 \%, C I=40.0-54.8 \%)$ as compared to the other age groups. Although the $\mathrm{GMPD} / \mu \mathrm{L}$ of blood was higher in males than in females and those aged 4-14 years, the differences were not significant. Overall, the prevalence of CMP was significantly higher in males $(19.7 \%, C I=15.0-25.5 \%)$, while AMP was significantly higher in participants aged 4-14 years $(27.2 \%, C I=21.1-34.4 \%$ ) (see Table 1 ). Among the malaria-positive individuals, CMP was significantly higher $\left(\chi^{2}=6.32, P=0.012\right)$ in males $(55.7 \%)$ than in females (35.2\%). In relation to age, CMP was highest in participants aged 36-45 years (70.6\%) and lowest in those aged $46-60$ years (37.5\%) as compared to those aged 4-14 years (42.5\%), 15-25 years (43.5\%) and 26-35 years $(45.5 \%)$. However, the differences were not significant $\left(\chi^{2}=4.83, P=0.31\right)$.
Anaemia prevalence was significantly higher in females $(74.0 \%, C I=67.9-79.3 \%)$ than in males $(54.3 \%$, $C I=47.7-60.7 \%)$, and in participants aged $4-14$ years (78.1\%, $C I=71.3-83.7 \%)$ (see Table 1 ).

\section{Influence of infection on haematological parameters}

As shown in Table 2, the prevalence of anaemia was significantly higher in individuals infected solely with $P$. falciparum $(70.4 \%, C I=61.9-7.7 \%)$ than in non-infected individuals $(59.5 \%, C I=53.5-65.3 \%)$. Likewise, anaemia prevalence was higher in those with co-infections $(88.0 \%$, $\mathrm{CI}=70.0-95.8 \%)$ than in those with a single infection $(67.7 \%, C I=60.4-74.6 \%)$ and in those non-infected. Individuals with co-infections had a significantly higher prevalence of moderate $(48.0 \%, C I=30.0-66.5 \%)$ and severe anaemia $(8.0 \%, C I=2.2-25.0 \%)$ than their counterparts with single infections. Similarly, moderate and severe anaemia was significantly higher in participants with coinfections than in those non-infected.

With regards to haematological values, individuals with co-infections had significantly lower mean $\mathrm{Hb}$ values $[9.8(1.9) \mathrm{g} / \mathrm{dL}]$ when compared to those infected with $P$. falciparum only, single infections and noninfected individuals. Similarly, lower mean values of Hct, $\mathrm{RBC}, \mathrm{WBC}$ and platelet counts were observed in those with co-infections compared to their single infection or non-infected peers (see Table 2).

The significant variation in mean Hct and RBC values were comparable with the $\mathrm{Hb}$ values, with the exception of the mean RBC values, between those with single infections and those non-infected, which was not significant. Participants with co-infections had significantly lower mean WBC counts compared to their single infection counterparts and those non-infected, as shown in Table 2. Contrary to the variation observed in other haematological values, participants infected with $T$. trichiura only and co-infection with $A$. lumbricoides had significantly higher mean platelet counts [248.3 $(90.6) \times 10^{9} / \mathrm{L}$ and $246.9(102.6) \times 10^{9} / \mathrm{L}$, respectively] than those non-infected. On the other hand, individuals with co-infections had significantly lower mean platelet counts $\left[155.8(68.9) \times 10^{9} / \mathrm{L}\right]$ than their noninfected counterparts.

The prevalence of leucopenia, microcytosis and thrombocytopenia in the studied population was 8.0, 11.1 and $30.5 \%$ respectively. Overall, leucopenia was significantly higher in individuals just with Ascaris infection $\left(\chi^{2}=12.3, P<0.001\right)$ and Ascaris-Trichuris coinfection $\left(\chi^{2}=8.9, P=0.003\right)$ when compared with their non-infected counterparts (Fig. 2). The prevalence of microcytosis was significantly higher $\left(\chi^{2}=15.7, P<0.001\right.$ and $\chi^{2}=7.15, P=0.008$, respectively) in individuals with co-infections (30.8\%) and single infections with $P$. falciparum $(16.0 \%)$. On the other hand, leucopenia was 
Table 2 Prevalence and severity of anaemia, and mean haematological values as influenced by category of infection

\begin{tabular}{|c|c|c|c|c|c|c|c|c|c|c|}
\hline \multirow{2}{*}{$\begin{array}{l}\text { Infection } \\
\text { category }\end{array}$} & \multirow[t]{2}{*}{$n$ and pairs } & \multirow{2}{*}{$\begin{array}{l}\text { Anaemia } \\
\%(n)\end{array}$} & \multicolumn{3}{|c|}{ Anaemia severity \% ( $n)$} & \multicolumn{5}{|c|}{ Mean (SD) values of: } \\
\hline & & & Mild & Moderate & Severe & $\mathrm{Hb}(\mathrm{g} / \mathrm{dL})$ & Hct (\%) & $\mathrm{RBC}\left(\times 10^{12} / \mathrm{L}\right)$ & WBC $\left(\times 10^{9} / L\right)$ & Platelet $\left(\times 10^{9} / \mathrm{L}\right)$ \\
\hline A.I only & 34 & $61.8(21)$ & $50.0(17)$ & $11.8(4)$ & $0.0(0)$ & $11.6(1.4)$ & $37.2(4.3)$ & $4.4(0.4)$ & $7.8(3.3)$ & $199.5(81.5)$ \\
\hline${ }^{\mathrm{a}}$ T.t only & 12 & $50.0(6)$ & $33.3(4)$ & $16.7(2)$ & $0.0(0)$ & $11.4(1.2)$ & $36.9(3.7)$ & $4.3(0.4)$ & $7.8(3.2)$ & $248.3(90.6)^{*}$ \\
\hline${ }^{b}$ Co-infection & 9 & $55.6(5)$ & $33.3(3)$ & $22.2(2)$ & $0.0(0)$ & $11.1(1.1)$ & $35.9(3.6)$ & $4.2(0.4)$ & $7.5(2.4)$ & $246.9(102.6)^{*}$ \\
\hline${ }^{c} P . f$ only & 125 & $70.4(88)$ & $46.4(28)$ & $23.2(29)$ & $0.8(1)$ & $11.1(1.7)$ & $34.4(5.7)$ & $4.2(0.6)$ & $8.9(3.3)$ & $187.3(82.2)$ \\
\hline${ }^{d} \mathrm{SI}$ & 162 & $67.7(110)$ & $46.3(75)$ & $21(34)$ & $0.6(1)$ & $11.2(1.7)$ & $35.0(5.5)$ & $4.2(0.6)$ & $8.7(3.3)$ & $191.7(82.1)$ \\
\hline${ }^{e}$ Co-infections & 25 & $88.0(22)$ & $32.0(8)$ & $48.0(12)$ & $8.0(2)$ & $9.8(1.9)$ & $30.5(5.9)$ & $3.8(0.7)$ & $6.8(2.9)$ & $155.8(68.9)$ \\
\hline${ }^{f}$ Negative & 262 & $59.5(156)$ & $45.0(118)$ & 14.1 (37) & $0.4(1)$ & 11.8 (1.8) & $36.9(5.9)$ & $4.4(0.6)$ & $8.4(3.4)$ & $189.2(82.6)$ \\
\hline Total & 450 & $64.2(289)$ & 44.9 (202) & $18.4(83)$ & $0.9(4)$ & 11.5 (1.8) & $35.8(6.0)$ & $4.3(0.6)$ & 8.4 (3.3) & $188.1(81.9)$ \\
\hline \multirow{4}{*}{$\begin{array}{l}P \text {-values of pairs } \\
\text { of comparisons }\end{array}$} & ${ }^{c} v_{v s}^{f}$ & 0.039 & 0.068 & & & $<0.001$ & $<0.001$ & 0.010 & 0.185 & 0.839 \\
\hline & ${ }^{d}$ Vs ${ }^{e}$ & 0.011 & 0.001 & & & $<0.001$ & 0.001 & 0.007 & 0.005 & 0.065 \\
\hline & ${ }^{d} v^{f}$ & 0.084 & 0.183 & & & 0.001 & 0.001 & 0.059 & 0.224 & 0.965 \\
\hline & $e^{e} v f$ & 0.001 & $<0.001$ & & & $<0.001$ & $<0.001$ & $<0.001$ & 0.019 & 0.049 \\
\hline
\end{tabular}

Abbreviations: A.I Ascaris lumbricoides, P.f Plasmodium falciparum, SI single infection, T.t Trichuris trichiura; vs: versus

${ }^{\mathrm{a}}$ T.t only $=$ single infection with $T . t$

${ }^{\mathrm{b}}$ Co-infection = infection with A.I and T.t

c Single infection with P.f

${ }^{\mathrm{d}} \mathrm{SI}=$ infection with eitherP.f,A.I or T.t

${ }^{\text {e}}$ Co-infections $=$ infection with P.f and A.I or P. f and T.t or P.f, A.I and T.t

${ }^{f}$ Negative $=$ individuals negative for all infections

$\mathrm{a}^{*}:$ Difference in mean platelet count for those infected with $T$. trichiura only and negative as determined by the Mann-Whitney $U$ test $(P=0.01)$

b*: Difference in mean platelet count for those infected with $A$. lumbricoides plus $T$. trichiura and those negative by Mann-Whitney $U$ test $(P=0$. 047)

Comparisons of pairs of proportions of anaemia prevalence of ${ }^{C} v^{f}{ }_{;} ;{ }^{d} v^{e} ;{ }^{d} v^{f}{ }^{f}$ and ${ }^{e}$ vs ${ }^{f}$ by $X^{2}$

Comparisons of pairs of proportions of anaemia severity of ${ }^{\mathrm{C}} \mathrm{vs}^{\mathrm{f}} ;{ }^{d} \mathrm{vs}^{\mathrm{e}}{ }^{\mathrm{d}}{ }^{\mathrm{d}} \mathrm{vs}^{\mathrm{f}}$ and $^{\mathrm{e}} \mathrm{vs}^{\mathrm{f}}$ by $X^{2}$

Comparison of pairs of mean haematological values of $\mathrm{Hb}, \mathrm{Hct}, \mathrm{RBC}, \mathrm{WBC}$ and platelets counts of ${ }^{\mathrm{C}}$ vs ${ }^{\mathrm{f}} ;{ }^{\mathrm{d}} \mathrm{vs}^{\mathrm{e}} ;{ }^{\mathrm{d}} \mathrm{vs}^{\mathrm{f}}{ }^{\mathrm{and}}{ }^{\mathrm{e}}$ vs ${ }^{\mathrm{f}}$ by Mann-Whitney $U$ test

$P$-values in bold are statistically significant

significantly higher $\left(\chi^{2}=14.0, P=0.001\right)$ in those with coinfections (26.9\%) than in those non-infected (see Fig. 3).

\section{Risk factors for anaemia}

A multiple linear regression model with $\mathrm{Hb}$ level as the dependent variable revealed that sex $(P=0.001)$, malaria parasite density $(P=0.001)$ and WBC count significantly influenced $\mathrm{Hb}$ values (see Table 3). As shown in Table 4 significant risk factors associated with anaemia included being $15-25$ years old (odds ratio, $O R=2.928$ ), $26-35$ years $(O R=2.832)$ and female $(O R=2.671)$, while participants with a normal body temperature were not at risk $(O R=0.622)$ of being anaemic.

\section{Risk factors for STH infections}

Examination of soil samples collected from various locations in the communities in order to identify continuous transmission hotspots revealed that 25 (41.7\%, CI =

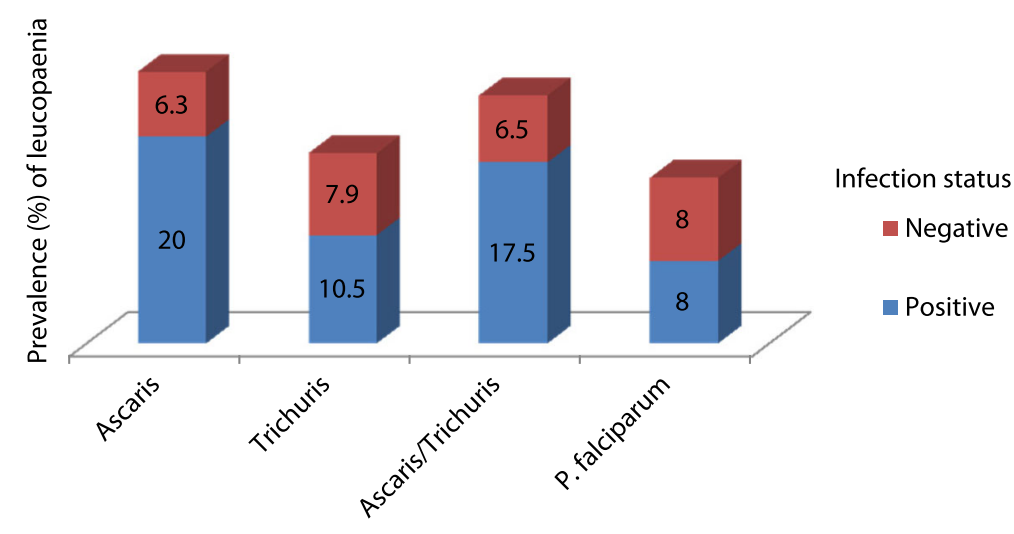

Parasitic infection

Fig. 2 Prevalence of leucopenia as influenced by infection status and parasite species 


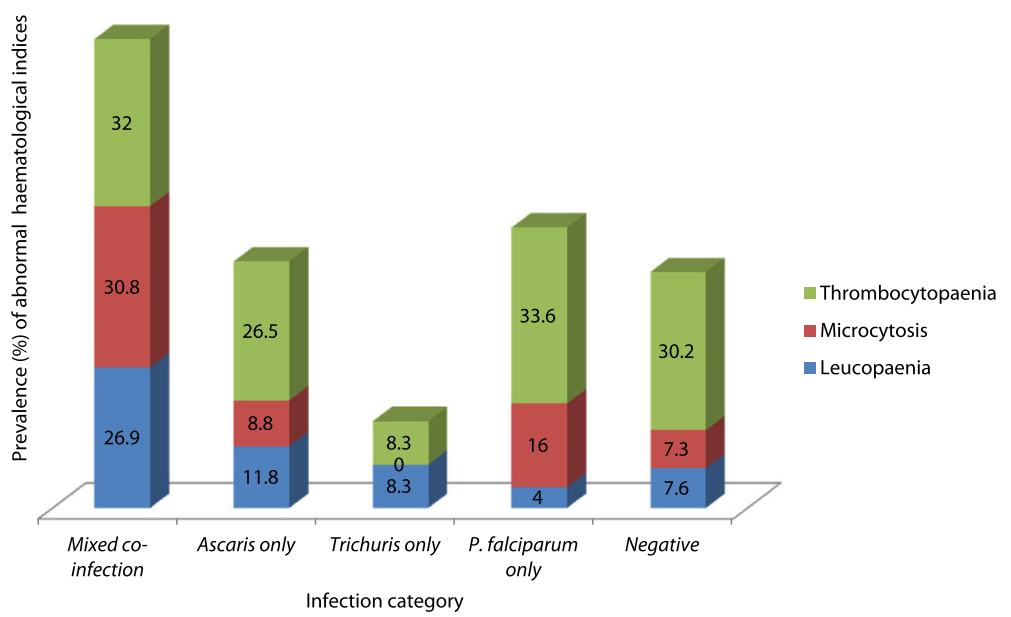

Fig. 3 Prevalence of leucopenia, microcytosis and thrombocytopenia, by (co-)infection category

30.0-54.3) of the 60 soil samples were contaminated with one or more STH species. Ascaris was the most common STH ova observed (36.7\%) and no contamination with hookworm larva was observed. As shown in Table 5, the contamination of soils from specific sites in the communities was significantly different $(P=0.003)$. The highest prevalence of STH ova was found in soil samples obtained from plantations (73.3\%) and the least prevalence of STH ova was found from around community taps (6.7\%). The significant differences in prevalences of Ascaris $(P=0.018)$ and Trichuris $(P=0.039)$ in soil samples from the different sites followed the same trend.

The binomial logistic regression analysis revealed that agroecosystem more specifically the tea plantation agroecosystem $(O R=3.07)$, age $(\mathrm{AOR}=1.49)$ and lack of access to potable water $(O R=2.25)$ were significantly associated with STH prevalence (see Tables 6 and 7). Participants working in the tea plantations were three times more likely to be infected with STHs, while those without access to potable water were two times more likely to be infected than their counterparts. Knowledge on helminth transmission and prevention and pretreatment with anthelmintics showed no association with the prevalence of STHs.

Table 3 Multiple linear regression analysis exploring the relationship between $\mathrm{Hb}$ and independent variables

\begin{tabular}{lrlrl}
\hline Parameter & B & SE & $t$-value & $P$-value \\
\hline Sex & 0.365 & 0.270 & 5.015 & $<\mathbf{0 . 0 0 1}$ \\
Age & 0.138 & 0.010 & 1.874 & 0.063 \\
Malaria parasitaemia (log transformed) & -0.268 & 0.177 & -3.375 & $\mathbf{0 . 0 0 1}$ \\
Temperature & -0.044 & 0.191 & -0.575 & 0.566 \\
WBC & 0.240 & 0.043 & 3.166 & $\mathbf{0 . 0 0 2}$ \\
\hline
\end{tabular}

$\mathrm{R}^{2}=0.256$

$P$-values in bold are statistically significant

\section{Discussion}

Lack of effective interventions for and surveillance of neglected populations may lead to the resurgence and outbreaks of STHs and P. falciparum malaria. This study was designed to investigate the epidemiology of STH and $P$. falciparum infections in two rural communities with intensive agricultural land use practices, some of which have the potential to create favourable environments for the development of STH ova and suitable mosquito

Table 4 Multinomial regression analysis examining factors associated with anaemia in the study population

\begin{tabular}{|c|c|c|c|}
\hline Parameter & $O R$ & $95 \% \mathrm{Cl}$ & $P$-value \\
\hline \multicolumn{4}{|l|}{${ }^{a}$ Age group } \\
\hline $4-14$ years & 0.73 & $0.32-1.69$ & 0.467 \\
\hline $15-25$ years & 2.93 & $1.17-7.33$ & 0.022 \\
\hline 26-35 years & 2.83 & $1.23-6.55$ & 0.015 \\
\hline 36-45 years & 1.84 & $0.79-4.31$ & 0.158 \\
\hline${ }^{\mathrm{b}}$ Female & 2.67 & $1.74-4.11$ & $<0.001$ \\
\hline${ }^{\circ}$ Malaria negative & 0.76 & $0.45-1.25$ & 0.272 \\
\hline${ }^{\mathrm{d}}$ Helminth positive & 0.78 & $0.37-1.65$ & 0.514 \\
\hline eCo-infection & 3.79 & $0.83-17.37$ & 0.086 \\
\hline${ }^{f}$ Absence of fever & 0.62 & $0.39-0.98$ & 0.043 \\
\hline \multicolumn{4}{|l|}{${ }^{9}$ WBC range } \\
\hline Low $\left(<4.5 \times 10^{9} / L\right)$ & 0.96 & $0.19-4.94$ & 0.960 \\
\hline Normal $\left(4.5-16.4 \times 10^{9} / \mathrm{L}\right)$ & 1.372 & $0.33-5.69$ & 0.662 \\
\hline \multicolumn{4}{|c|}{ 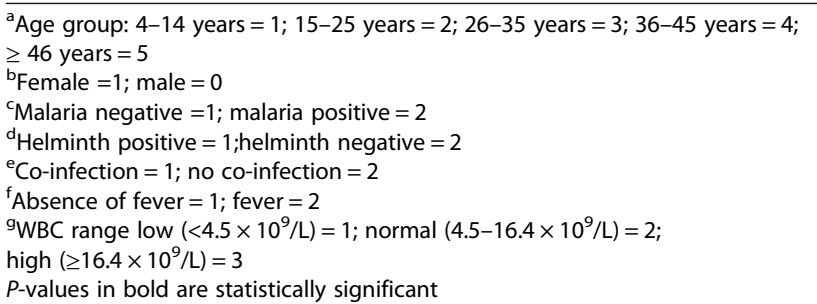 } \\
\hline
\end{tabular}


Table 5 Prevalence of STH ova in soils from various sites in the communities

\begin{tabular}{|c|c|c|c|c|c|c|}
\hline Factor & & No. of samples examined & STH positive \% ( $n)$ & Ascaris \% (n) & Trichuris \% (n) & Ascaris + Trichuris \% ( $n$ ) \\
\hline \multirow[t]{2}{*}{ Community } & Tole & 20 & $50.0(10)$ & $45.0(9)$ & $30.0(6)$ & $20.0(4)$ \\
\hline & Ekona & 40 & $37.5(15)$ & $32.5(13)$ & $12.5(5)$ & $7.5(3)$ \\
\hline$P$-value & & & 0.355 & 0.344 & 0.099 & 0.155 \\
\hline \multirow[t]{4}{*}{ Sites } & Pit toilets & 15 & $46.7(7)$ & $47.6(7)$ & $13.2(2)$ & $13.2(2)$ \\
\hline & Taps & 15 & $6.7(1)$ & $6.7(1)$ & $0.0(0)$ & $0.0(0)$ \\
\hline & Surroundings & 15 & $40.0(6)$ & $33.3(5)$ & $20.0(3)$ & $13.2(2)$ \\
\hline & Plantations & 15 & $73.3(11)$ & $60.0(9)$ & $40.0(6)$ & $20.0(3)$ \\
\hline Total & & 60 & $41.7(25)$ & $36.7(22)$ & $18.3(11)$ & $11.7(7)$ \\
\hline$P$-value & & & 0.003 & 0.018 & 0.039 & 0.381 \\
\hline
\end{tabular}

$P$-values in bold are statistically significant

Table 6 Unadjusted OR of factors associated with the prevalence of STH infections using the binary logistic regression model

\begin{tabular}{|c|c|c|c|c|}
\hline Variable & $n$ & STH prevalence \% $(n)$ & Unadjusted ORs (95\% Cl) & $P$-value \\
\hline Agroecosystem & & & & 0.007 \\
\hline Tea & 165 & $21.2(35)$ & $3.07(1.51-6.22)$ & 0.002 \\
\hline Banana & 127 & $11.0(14)$ & $1.78(0.79-4.04)$ & 0.166 \\
\hline Palm & 158 & $8.9(14)$ & Reference & \\
\hline \multicolumn{5}{|l|}{ Demographic information } \\
\hline \multicolumn{5}{|l|}{ Age groups } \\
\hline Age (years) & & & & 0.330 \\
\hline $4-14$ & 169 & $14.2(24)$ & $0.35(0.09-1.32)$ & 0.122 \\
\hline $15-25$ & 56 & $12.5(7)$ & $0.36(0.09-1.38)$ & 0.135 \\
\hline $26-35$ & 96 & $11.5(11)$ & $0.76(0.25-2.35)$ & 0.633 \\
\hline $36-45$ & 88 & $13.6(12)$ & $1.10(0.36-3.35)$ & 0.874 \\
\hline$\geq 46$ & 41 & $22.0(9)$ & & \\
\hline \multicolumn{5}{|l|}{ Gender } \\
\hline Female & 227 & $17.2(39)$ & $1.40(0.77-2.54)$ & 0.269 \\
\hline Male & 223 & $10.8(24)$ & Reference & \\
\hline \multicolumn{5}{|l|}{ Education level of household head } \\
\hline Education level & & & & 0.485 \\
\hline Primary & 277 & $12.6(33)$ & $0.52(0.16-1.68)$ & 0.274 \\
\hline Post-primary & 150 & $14.0(21)$ & $0.66(0.19-2.24)$ & 0.505 \\
\hline \multicolumn{5}{|l|}{ Malaria parasite status } \\
\hline Positive & 150 & $16.7(25)$ & $1.38(0.73-2.54)$ & 0.302 \\
\hline Negative & 300 & $12.7(38)$ & Reference & \\
\hline \multicolumn{5}{|l|}{ Amenities and hygiene } \\
\hline Lack access to potable water & 80 & $18.8(15)$ & $2.25(1.29-3.91)$ & 0.004 \\
\hline Access to potable water & 370 & $13.0(48)$ & Reference & \\
\hline Seldom wearing shoes & 12 & $33.3(4)$ & $0.30(0.07-1.33)$ & 0.114 \\
\hline Always wearing shoes & 438 & $13.5(59)$ & Reference & \\
\hline Cemented house floor & 432 & $14.1(61)$ & $0.36(0.06-2.15)$ & 0.264 \\
\hline House floor not cemented & 18 & $11.1(2)$ & Reference & \\
\hline
\end{tabular}


Table 7 Final binary logistic regression model showing factors associated with the prevalence of STHs

\begin{tabular}{|c|c|c|c|c|}
\hline Variable & $n$ & Adjusted $O R$ & $95 \% \mathrm{Cl}$ & $P$-value \\
\hline Agroecosystem & & & & 0.002 \\
\hline Tea & 165 & 3.23 & $1.67-6.42$ & 0.001 \\
\hline Banana & 127 & 1.75 & $0.78-3.95$ & 0.177 \\
\hline Palm & 158 & Reference & & \\
\hline Age & 450 & 1.49 & $1.12-1.98$ & 0.007 \\
\hline \multicolumn{5}{|l|}{ Malaria parasite status } \\
\hline Positive & 150 & 0.70 & $0.39-1.28$ & 0.246 \\
\hline Negative & 300 & Reference & & \\
\hline \multicolumn{5}{|l|}{ Amenities and hygiene } \\
\hline Lack access to potable water & 80 & 2.20 & $1.35-3.58$ & 0.002 \\
\hline \multicolumn{5}{|l|}{ Access to potable water } \\
\hline Cemented house floor & 432 & 0.55 & $0.12-2.65$ & 0.459 \\
\hline House floor not cemented & 18 & Reference & & \\
\hline
\end{tabular}

$P$-values in bold are statistically significant

breeding sites. This scenario is likely to influence the transmission patterns of these infections, hence leading to unfavourable health conditions for the farmers and their families living in such communities [11, 29].

The overall prevalence of STHs in the study population of $14.0 \%$ is lower than the $38.3 \%$ reported in children in the Mount Cameroon area [3] and $43.8 \%$ in children in Ekona [2]. On the other hand, the observed prevalence is higher than the $2.5 \%$ reported in a recent study of various sites in the Mount Cameroon area [20]. The observed decrease in overall prevalence in this rural setting may be credited to the impact of helminth control strategies employed by the government. Current control strategies have focused on preventive chemotherapy through mass drug administration, in which atrisk populations such as school-age children and pregnant women are treated once or twice per year with benzimidazoles. While preventive chemotherapy can greatly reduce morbidity from helminth infections, reinfection may typically occur rapidly following treatment [30]. This is especially likely in children living in rural areas and farming communities with low levels of sanitation. In addition to the lack of adequate faecal disposal facilities, adults including farmers who are often left out of the national de-worming programme [21] may harbour a good number of these worms, hence serving as a main source of faecal contamination with helminth ova in their surroundings.

Only two of the three common STHs (A. lumbricoides and $T$. trichiura) were observed in the studied population. A similar observation was made by Zeukeng et al. [19] in Mfou Health District in Cameroon and Nkengazong et al. [1] in Marumba II who reported that hookworm was rare in the entire Mount Cameroon area. However, as most plantation workers are provided with personal protective working boots, hookworm infections that result from direct percutaneous invasion of infective larvae found in the soil did not have the opportunity to penetrate the skin, while Ascaris and Trichuris eggs which are transmitted faecal orally could easily be picked up. Furthermore, findings from this study revealed an absence of hookworm larvae in the soil samples collected from specific sites in the communities, even though a $41.7 \%$ contamination with geohelminth eggs was observed. The presence of eggs in the soil is indicative of faecal pollution corroborating the inadequacy of toilet facilities in the area. Hence, in addition to the provision of appropriate means of faecal disposal in rural communities, there is a need to incorporate behavioural change and health education in the control programme, if the desired goal of STH elimination is to be achieved.

The higher prevalence of STHs (A. lumbricoides and T. trichiura) infections in participants from the tea plantation area than in their counterparts from the banana and palm plantation areas is not unusual. Tea plantation workers were three times more likely to be infected with STHs than their counterparts. Elsewhere, higher prevalence of STHs than those observed in this study have been linked to tea farming communities [31]. The presence of favourable factors for the growth and transmission of STHs in the tea plantation communities could possibly be linked to the fact that the production of tea in Cameroon is not GLOBALGAP certified, while the production of banana and palm by the CDC is. GLOBALGAP is an internationally recognised set of farm standards dedicated to good agricultural practices, and certification assures adherence to the standards of health, safety and welfare of workers as well as the environment. Moreover, because tea is a shrub with a closed canopy, it may provide a suitable cover and inspire individuals to defecate more freely than in the open canopies of banana and palm plantations. Defecation practices in other tea growing communities have been reported as a strong risk factor for acquiring STH infections [31].

The widespread prevalence of STHs in more females than males is in line with studies carried out in Kumba, Cameroon and tea growing communities in India [31, 32]. On the other hand, studies in the same area [33] and in Mfou Health District [19] revealed the contrary. The higher prevalence and density of Ascaris and Trichuris infections may be related to the population at risk of infection in the different agroecosystem and gender-related roles. Even though the overall numbers of males and females examined in this study were similar, more women $(55.8 \%)$ than men $(44.2 \%)$ were working as tea harvesters in the plantation. Furthermore, girls have been reported to be more likely to commence working as tea pickers than boys who engage in more strenuous factory work [31]. 
Although the univariate analysis did not significantly associate any age group with STH prevalence, the multivariate analysis (see Table 5) identified age as a risk factor for STH infection. Several studies have been carried out among at-risk groups such as (pre)school age children and pregnant women in various locations $[1,3,33,34]$, however, fewer studies have examined the prevalence of STHs in other age groups at risk of infection. The prevalence of STHs was highest in the 46-60 years age group, which is in contrast to the highest prevalence observed in school-age children in rural communities of Mfou Health District [19]. In addition, out of the 63 individuals with STH infections in this study, the majority (61.9\%) were $\geq$ 15 years of age. The prevalence of STHs in this age bracket may be attributed to this age group participating in agricultural activities such as hand picking of weeds, harvesting of tea leaves and palm seeds, and planting, as well as being linked to poor hygienic practices while working in the plantations, which are contaminated with helminth ova. Furthermore, these age groups are excluded from the government-sponsored national helminth control programme.

Individuals without access to potable water were two times more likely to be infected than their counterparts. Whilst performing farming activities such as harvesting or weeding, hands are likely to come into physical contact with contaminated soil. In addition, the majority of the soil samples collected from the plantations were contaminated with either Ascaris or Trichuris ova, indicating faecal pollution. In the absence of access to potable water, such individuals are likely to eat food without proper washing of their hands. Hence, for the control of helminths to be effective, there is a paramount need for an improvement of sanitary habits through education and provision of potable water accessible to all.

The overall prevalence of malaria (33.3\%) is comparable to observations at various sites and in different populations in the Mount Cameroon area [20, 35, 36], but lower than the $77.2 \%$ observed in Mfou [19]. Worthy of note is the reported decrease in malaria parasite prevalence that has been credited to the intensification of malaria control measures in the Mount Cameroon area [35]. However, the diverse geo-ecological and climatic conditions of the Mount Cameroon area and other regions might influence malaria vector breeding and distribution as well as malaria parasite prevalence in different areas. Nonetheless, while the higher prevalence of malaria parasites in the youngest age group is in line with other studies [19, 36, 37], the highest proportion of CMP observed in participants aged 36-45 years is remarkable. This unusual finding merits further investigation, as acquired immunity to malaria is both exposure- and age-dependent, and adults are likely to have developed some degree of immunity as a result of repeated infections [38].

While the significant symptomatology of malaria parasite in males may be linked to the high parasite densities, on the contrary, a significant tendency of asymptomatic malaria was observed in participants with high malaria parasite density from the palm plantation area and children belonging to the 4-14 age group. Although high parasitaemia has been associated with an increase in disease severity, this is not always the case as parasites that circulate in peripheral blood do not always accurately reflect the number of parasites due to sequestration [39]. This notwithstanding, the presence of a greater number of asymptomatic infections in the studied population which may often go undetected and untreated thus resulting in a major source of gametocytes for local mosquito vectors [40] poses an unseen hurdle to the control efforts against malaria transmission in the area.

The prevalence of anaemia (64.2\%) found in this study is significantly higher than the $42 \%$ reported by a crosssectional study conducted in Mfou [19]. While the higher prevalence of anaemia observed in female participants may be credited to the higher physiological demands for iron [41] by those in the reproductive age group, especially menstruating women, the higher prevalence of anaemia in participants aged 4-14 years may be attributed to the occurrence of significantly high prevalence and density of malaria parasites. Furthermore, the multivariate analysis revealed that participants aged 15-25 years and 26-35 years are at a 2.8 -fold risk of acquiring anaemia, which may be credited to the higher prevalence of CMP in these groups. In line with previous studies $[42,43]$, anaemia prevalence was significantly higher in individuals who were malaria-positive. Worthy of note also is that the highest prevalence of anaemia was observed in those with co-infections.

The prevalence of STH and P. falciparum co-infections in the population $(5.6 \%)$ was lower $(22.1 \%)$ than that reported in a study of the rural communities in Mfou [19]. While single infection with any STH did not increase the odds of being anaemic, co-infections exerted a significant influence on the prevalence and severity of anaemia in the cohort. The prevalence of moderate and severe anaemia in participants with co-infections is at least two folds higher than the prevalence in those with single infection of any STH and non-infected individuals. Anaemia as a consequence of co-infections or polyparasitism has been highlighted in previous research [2, 44]. The increased presence of moderate and severe anaemia in participants with co-infections may be attributed to the dual impact of the mechanisms causing anaemia. While malaria may cause anaemia through a combination of haemolysis, increased splenic clearance of infected and uninfected red blood cells, shortened red cell life span and cytokine- 
induced dyserythropoiesis [45-47], the impact of Ascaris infection on anaemia is less clear, although it may influence the nutritional status [48]. Findings from this study revealed no relationship between Ascaris or Trichuris infections and the $\mathrm{Hb}$ level. Nevertheless, the fact that up to $59.5 \%$ of individuals negative for all parasite species were anaemic- with some having moderate or severe anaemia- highlights the significant contribution of other factors to anaemia that this study did not investigate.

The $\mathrm{Hb}, \mathrm{Hct}, \mathrm{RBC}, \mathrm{WBC}$ and platelet values were significantly lower in individuals with co-infections as compared to single infections with either STH or $P$. falciparum. The similarities in mean red cell indices in those with a single STH infection and lower values in those co-infected with a helminth only or P. falciparum single infection accentuate the influence of any coinfection and $P$. falciparum infection on haematological parameters. Although all mean platelet counts were within the normal range $\left(150-400 \times 10^{9} \mathrm{~L}\right)$, participants infected with Trichuris and co-infection with a STH had significantly higher mean platelet counts than their counterparts. While anecdotal case reports exist on trichuriasis and laboratory values $[49,50]$, in line with the findings of this study, the platelet counts were within the normal range. Nevertheless, the significant increase in platelet counts warrants further investigation to specifically clarify the role of Trichuris leading to such an increase. On the other hand, those with co-infections had significantly lower platelet counts that approached the lower limit of normal values. This may be attributed to the corollary of $P$. falciparum on platelet counts as thrombocytopenia has been reported as a common feature of falciparum malaria $[51,52]$. Some of the speculated mechanisms leading to thrombocytopenia include: coagulation disturbances, shortened platelet life span in peripheral blood and sequestration in non-splenic areas, bone marrow alterations, immunological destruction due to antiplatelet IgG, oxidative stress and, partly, pseudothrombocytopenia due to clumping of platelets [52-54].

Even though the mean WBC counts in participants with single infection of Ascaris or Trichuris were similar, the prevalence of leucopenia was significantly higher in those infected with Ascaris and in those with co-infections of Ascaris and Trichuris. The low prevalence of helminth infections and leucopenia in the studied population limits the power of this finding. In addition to this limitation, eosinophilia, which is known to occur alongside helminth infection, was not investigated to account for the variation in the observation. Nonetheless, the fact that helminth infections were common in adolescents and the adult population, while eosinophilia has been shown to be less frequent as age increases [55] merits further investigation into the effects of Ascaris infection on total white cell and differential counts.
Haematological manifestations such as microcytosis and leucopenia observed in the participants have been linked to $P$. falciparum infection in a previous study [36]. The high occurrence of microcytosis in the two groups with the highest prevalence of anaemia in individuals with co-infections and $P$. falciparum single infection, is not surprising. Microcytosis have been associated with lower $\mathrm{Hb}$ levels $[56,57]$. However, the occurrence of microcytosis in individuals negative for STH and $P$. falciparum infections and the high prevalence of anaemia in these individuals suggests that an undiagnosed iron deficiency possibly contributes to the occurrence of anaemia [43].

\section{Conclusions}

The findings of this study suggest that STHs, malaria and anaemia are still of public health concern among plantation communities in the Mount Cameroon area. Coinfections negatively influenced haematological values and indices. The tea plantation area, age and lack of access to potable water constitute significant risk factors for acquiring STH infections, while the age groups $15-25$ years and 26-35 years, and being female were significant risk factors for acquiring anaemia.

In spite of governmental efforts to control these infections, the presence of infections in groups not targeted during control programmes as well as environmental contamination with helminth ova constitute a barrier to the achievement of the desired goal of reduction or eradication. In addition to the inclusion of other at-risk groups in control programmes, potable water should be provided in plantations and communities, and environmental sanitation needs to be improved.

\section{Additional file}

Additional file 1: Multilingual abstract in the five official working languages of the United Nations. (PDF $748 \mathrm{~kb}$ )

\begin{abstract}
Abbreviations
AMP: Asymptomatic malaria parasitaemia; CDC: Cameroon Development Corporation; Cl: Confidence interval; CMP: Clinical malaria parasitaemia; epg: Eggs per gram; GMED: Geometric mean egg density; GMPD: Geometric mean parasite density; Hb: Haemoglobin; Hct: Haematocrit; MCH: Mean corpuscular haemoglobin; MCV: Mean corpuscular volume; OR: Odds ratio; RBC: Red blood cell; SD: Standard deviation; STH: Soil-transmitted helminth; WBC: White blood cell; WHO: World Health Organization
\end{abstract}

\section{Acknowledgements}

The authors appreciate the support and cooperation of the farming families in Tole and Ekona who took part in the study. We equally express our gratitude to Mr. Geraud Tasse for the GIS mapping and the medical personnel who aided in the clinical examination and collection of the samples.

\section{Funding}

This work was supported by the special fund for research and modernisation given to the authors by the Government of Cameroon. 


\section{Availability of data and materials}

All datasets on which the conclusions of the research rely are presented in this paper.

\section{Authors' contributions}

IUNS was involved in all phases of the study, including study design, data collection, data analysis, data interpretation and writing of the paper. GBN was involved in the literature search, collection of data and laboratory examination of samples. HKK was involved in the study design, supervision and revision of the paper. All authors read and approved the final manuscript.

\section{Authors' information}

IUNS: PhD and Senior Lecturer of Parasitology, Department of Zoology and Animal Physiology, University of Buea.

GBN: MSc Zoology, Department of Zoology and Animal Physiology, University of Buea.

HKK: PhD and Associate Professor of Medical Parasitology, Department of Medical Laboratory Sciences, University of Bamenda.

\section{Competing interests}

The authors declare that they have no competing interests.

\section{Ethics approval and consent to participate}

Ethical approval for this study was obtained from the Institutional Review Board (IRB) (2014/228/UB/FHS/RB) of the Faculty of Health Sciences, University of Buea, after administrative clearance from the South West Regional Delegation of Public Health was obtained. The objectives and potential benefits of the study were explained to individuals during sensitisation visits before giving out informed consent or assent forms to the potential adult or child participants. The purpose and methodology of the study was explained to the individuals and they were given the opportunity to ask questions. Participation in the study was voluntary. Only participants who gave written and/or verbal consent or assent took part in the study. As recommended by the IRB, participants including parents or guardian of children who could not read or write had their verbal consent or assent documented in the form by the research team before enrolment into the study. Clinical examination was performed by a qualified clinician in the research team-all cases of malaria were prescribed appropriate treatment and cases of STH were treated with mebendazole. Confidentiality was ensured by coding questionnaires and laboratory entries in the database were password-protected.

\section{Author details}

'Department of Zoology and Animal Physiology, University of Buea, Buea, Cameroon. ${ }^{2}$ Department of Medical Laboratory Sciences, University of Bamenda, Bamenda, Cameroon.

\section{Received: 18 February 2016 Accepted: 17 February 2017}

\section{Published online: 16 March 2017}

\section{References}

1. Nkengazong L, Njiokou F, Wanji S, Teukeng F, Enyong P, Asonganyi T. Prevalence of soil transmitted helminths and impact of Albendazole on parasitic indices in Kotto-Barombi and Marumba II villages (South-West Cameroon). Afr J Environ Sci Technol. 2010;4:115-21.

2. Kimbi HK, Lum E, Wanji S, Mbuh JV, Nyanga JLN, Eyong ECJ, et al. Coinfections of asymptomatic malaria and soil-transmitted helminths in school children in localities with different levels of urbanization in the Mount Cameroon Region. J Bacteriol Parositol. 2012;3:134.

3. Nkuo-Akenji TK, Chi PC, Cho JF, Ndamukong KK, Sumbele I. Malaria and helminth co-infection in children living in a malaria endemic setting of mount Cameroon and predictors of anemia. J Parasitol. 2006;92:1191-5.

4. Ministry of Public Health, Cameroon. Plan stratégique national de lutte contre le paludisme 2011-2015. Ministère de la Santé Publique. Cameroun. 2012:82p.

5. Utzinger J, Vounatsou P, N'Goran EK, Tanner M, Booth M. Reduction in the prevalence and intensity of hookworm infections after praziquantel treatment for schistosomiasis infection. Int J Parasitol. 2002;32:759-65.

6. Brooker S. Estimating the global distribution and disease burden of intestinal nematode infections. Adding up the numbers-a review. Int J Parasitol. 2010;40:1137-44.
7. Bethony J, Brooker S, Albonico M, Geiger SM, Loukas A, Diemert D, et al. Soil-transmitted helminth infections: ascariasis, trichuriasis, and hookworm. Lancet. 2006;367:1521-32.

8. karan A, Chapman GB, Galvani A. The influence of poverty and culture on the transmission of parasitic infections in rural Nicaraguan Villages $J$ Parasitol Res. 2012 article ID,478292. doi.org/10.1155/2012/478292

9. Nkuo-Akenji T, Ntonifor NN, Ndukum MB, Abongwa EL, Nkwescheu A, et al. Environmental factors affecting malaria parasite prevalence in rural Bolifamba, South West Cameroon. Afr J Health Sci. 2006;13:40-6.

10. Messina JP, Taylor SM, Meshnick SR, Linke AM, Tshefu AK, et al. Population, behavioural and environmental drivers of malaria prevalence in the Democratic Republic of Congo. Malar J. 2011;10:161.

11. Matthys B, Tschannen AB, Tian-Bi NT, Comoé H, Diabaté S, Traoré M, et al. Risk factors for Schistosoma mansoni and hookworm in urban farming communities in western Côte d'Ivoire. Trop Med Int Health. 2007;12:709-23.

12. Briët OJ, Dossou-Yovo J, Akodo E, van de Giesen N, Teuscher TM. The relationship between Anopheles gambiae density and rice cultivation in the savannah zone and forest zone of Côte d'Ivoire. Trop Med Int Health. 2003:8:439-48.

13. Mboera LE, Senkoro KP, Rumisha SF, Mayala BK, Shayo EH, Mlozi MR. Plasmodium falciparum and helminth coinfections among schoolchildren in relation to agro-ecosystems in Mvomero District, Tanzania. Acta Trop. 2011;20:95-102.

14. Nacher M, Gay F, Singhasivanon P, Krudsood S, Treeprasertsuk S, Mazier D, Vouldoukis I, Looareesuwan S. Ascaris, lumbicoides infection is associated with protection from cerebral malaria. Parasite Immunol. 2000;22:107-13.

15. Briand V, Watier L, LE Hesran JY, Garcia A, Cot M. Coinfection with Plasmodium falciparum and schistosoma haematobium: protective effect of schistosomiasis on malaria in senegalese children? Am J Trop Med Hyg. 2005;72:702-7.

16. Druilhe $P$, Tall A, Sokhna C. Worms can worsen malaria: towards a new means to roll back malaria? Trends Parasitol. 2005;21:359-62.

17. Menendez C, Fleming AF, Alonso PL. Malaria-related anaemia. Parasitol Today. 2000;16:469-76.

18. Brooker S, Akhwale W, Pullan R, Estambale B, Clarke SE, Snow RW, et al. Epidemiology of Plasmodium-helminth co-infection in Africa: populations at risk, potential impact on anemia and prospects for combining control. Am J Trop Med Hyg. 2007;77(65):88-98.

19. Zeukeng F, Tchinda VHM, Bigoga JD, Seumen CHT, Ndzi ES, Abonweh G, et al. Co-infections of malaria and geohelminthiasis in two rural communities of Nkassomo and Vian in the Mfou Health District, Cameroon. Plos Negl Trop Dis. 2014;8:e3236.

20. Ndamukong-Nyanga JL, Kimbi HK, Sumbele IUN, Nana Y, Bertek SC, Ndamukong KJN, et al. A Cross-sectional study on the influence of altitude and urbanisation on co-infection of malaria and soil-transmitted helminths in Fako Division. South West Cameroon: Internationation Journal of Tropical Disease and Health. 2015;8:150-64.

21. Tchuem-Tchente TLA, N'Goran EK. Schistosomiasis and soil-transmitted helminthiasis control in Cameroon and Côte d'Ivoire: Implementing control on a limited budget. Parasitology. 2009;136:1739-45.

22. Wanji S, Tanke T, Atanga SN, Ajonina C, Tendongfor N, Fontenille D. Anopheles species of the Mount Cameroon Region; bitings habits, feeding behaviour and entomological inoculation rates. Trop Med Int Health. 2003;8:643-9.

23. Bryan FJ. The design and analysis of research studies. UK: University of Otago, Cambridge University Press; 1992.

24. Cheesbrough M. District laboratory practice in tropical countries. Part1\& 2 . New York: Cambridge University Press; 2009.

25. WHO Iron deficiency anaemia: assessment, prevention and control, a guide for programme managers. Geneva, Switzerland: World Health Organization Publication;2001.http://www.who.int/nutrition/publications/micronutrients/ anaemia_iron_deficiency/NHO_NHD_01.3/en/index.html. Accessed 17Apr 2016.

26. Calis JCJ, Phiri KS, Faragher BE, Brabin BJ, Bates I, Cuevas LE, et al. Severe anaemia in Malawian children. N Engl J Med. 2008;358:888-99.

27. Montresor A, Crompton DWT, Hall A, Bundy DAP, Savioli L. Guidelines for the evaluation of soil-transmitted helminthiasis and schistosomiasis at community level. Geneva: World Health Organization; 1998. WHO document WHO/CDS/ SIP/98.1 (available from the Programme Parasitic Diseases andVector Control, World Health Organization, CH 1211 Geneva 27, Switzerland).

28. Kagei $\mathrm{N}$. Techniques for the measurement of environmental pollution by infection stages of soil-transmitted helminths. In Yokogawa M. Collected papers on the control of soil transmitted helminthiasis. APCO. 1983;11: 27-46. 
29. Yadouléton A, N'Guessan R, Allagbé H, Asidi A, Boko M, Osse R, et al. The impact of the expansion of urban vegetable farming on malaria transmission in major cities of Benin. Parasit Vectors. 2010;3:118.

30. Jia T-W, Melville S, Utzinger J, King CH, Zhou X-N. Soil-transmitted helminth reinfection after drug treatment: a systematic review and meta-analysis. Plos Negl Trop Dis. 2012;6(5):e1621.

31. Traub RJ, Irobertson ID, Irwin P, Mencke N, Thompson RCA. The prevalence, intensities and risk factors associated with geohelminth infection in teagrowing communities of Assam, India. Trop Med Int Heallth. 2004;9:688-701.

32. Adio MB, Ndamukong KJ, Kimbi HK, Mbuh JV. Malaria and intestinal helminthiasis in school children of Kumba urban area, Cameroon. East Afri Med J. 2004;81:583-8.

33. Ndamukong KJ, Ayuk MA, Dinga JS, Akenji TN, Ndiforchu VA. The pattern of soil-transmitted nematode infections in primary school children of Kumba Health District, South West, Camerooon. Afr J Health Sci. 2000;7:103-6.

34. Belyhun Y, Medhin G, Amberbi A, Erko B, Hanlon C, Alem A, et al. Prevalence and risk factors for soil-transmitted helminth infection in mothers and their infants in Butajira, Ethiopia: a population based study. BMC Public Healt. 2010;10:21.

35. Sumbele IUN, Ning TR, Bopda OSM, Nkuo-Akenji T. Variation in malariometric and red cell indices in children in the Mount Cameroon area following enhanced malaria control measures: evidence from a repeated cross-sectional study. Malar J. 2014;13:334

36. Kimbi HK, Sumbele IUN, Nweboh M, Anchang-Kimbi JK, Lum E, Nana N, et al. Malaria and haematologic parameters of pupils at different altitudes along the slope of Mount Cameroon: a cross-sectional study. Malar J. 2013;12:193.

37. Noland GS, Graves PM, Sallau A, Eigege A, Emukah E, Patterson AE, et al. Malaria prevalence, anaemia and baseline intervention coverage prior to mass net distributions in Abia and Plateau States, Nigeria. BMC Infect Dis. 2014;14:168

38. Bodker R, Msangeni HA, Kisinza W, Lindsay SW. Relationship between the intensity of exposure to malaria parasites and infection in the Usambara Mountains, Tanzan. Am J Trop Med Hyg. 2006;74:716-23.

39. Laishram DD, Sutton PL, Nanda N, Sharma VL, Sobti RC, Carlton JM, et al. The complexities of malaria disease manifestations with a focus on asymptomatic malaria. Malar J. 2012;11:29.

40. Alves FP, Gil LH, Marrelli MT, Ribolla PE, Camargo EP, Da Silva LH. Asymptomatic carriers of Plasmodium sp. as infection source for malaria vector mosquitoes in the Brazilian Amazon. J Med Entomol. 2005:42:777-9.

41. Viteri FE. Effective iron supplementation does not happen in isolation. Am J Clin Nutr. 1997;65:889-90.

42. Abanyie FA, McCracken C, Kirwan P, Molloy SF, Asaolu SO, Holland CV. Ascaris co-infection does not alter malaria induced anaemia in a cohort of Nigerian preschool children. Malar J. 2013;12:1.

43. Sumbele IUN, Kimbi HK, Ndamukong-Nyanga JL, Nweboh M, AnchangKimbi JK, Lum E, et al. Malarial anaemia and anaemia severity in apparently healthy primary school children in urban and rural settings in the Mount Cameroon Area: Cross sectional survey. Plos One. 2015:10:e0123549.

44. Midzi N, Mtapuri-Zinyowera S, Mapingure MP, Sangweme D, Chirehwa MT, Brouwer KC, et al. Consequences of polyparasitism on anaemia among primary school children in Zimbabwe. Acta Trop. 2010;115:103-11.

45. Looareesuwan S, Davis TM, Pukrittayakamee S, Supanaranond W, Desakorn $\checkmark$, Silamut $K$, et al. Erythrocyte survival in severe falciparum malaria. Acta Trop. 1991:48:263-70.

46. Dondorp AM, Angus BJ, Chotivanich K, Silamut K, Ruangveerayuth R, Hardeman MR, et al. Red blood cell deformability as a predictor of anaemia in severe falciparum malaria. Am J Trop Med Hyg. 1999;60:733-7.

47. Crawley J. Reducing the burden of anaemia in infants and young children in malaria-endemic countries of Africa: from evidences to action. Am J Trop Med Hyg. 2004;71:25-34.

48. de Silva BR, Brooker S, Hotez PJ, Montressor A, Engels D, Savioli L. Soiltransmitted helminth infections: updating the global picture. Trends Parasitol. 2003:27:547-51.

49. Ok KS, Kim YS, Song JH, Lee JH, Ryu SH, Lee JH, et al. Trichuris trichiura infection diagnosed by colonoscopy: case reports and review of literature. Korean J Parasitol. 2009;47:275-80.

50. Wang DD, Wang XL, Wang XL, Wang S, An CL. Trichuriasis diagnosed by colonoscopy: case report and review of the literature spanning 22 years in mainland China. Int J Infect Dis. 2013:17:e1073-5.
51. Kochar DK, Das A, Kochar A, Middha S, Acharya J, Tanwar GS, et al. Thrombocytopenia in Plasmodium falciparum, Plasmodium vivax and mixed infection malaria: a study from Bikaner (Northwestern India). Platelets. 2010:21:623-7.

52. Lacerda MVG, Mourão MPG, Coelho HCC, Santos JB. Thrombocytopenia in malaria: who cares? Mem Inst Oswaldo Cruz. 2011;106(Suppl I):52-63.

53. Erel O, Vural H, Aksoy N, Aslan G, Ulukanligil M. Oxidative stress of platelets and thrombocytopenia in patients with vivax malaria. Clin Biochem. 2001:34:341-4.

54. Scott CS, Van Zy D, Ho E, Ruivo L, Mendelow B, Coetzer TL. Thrombocytopenia in patients with malaria: automated analysis of optical platelet counts and platelet clumps with the Cell Dyn CD4000 analyser. Clin Lab Haematol. 2002;24:295-302.

55. Bejon P, Mwangi TW, Lowe B, Peshu N, Hill AVS, Marsh K. Helminth infection and eosinophilia and the risk of Plasmodium falciparum malaria in 1- to 6year-old children in a malaria endemic area. Plos Negl Trop Dis. 2008;2:e164.

56. Cornet M, Le Hesran J-UL, Fievet N, Cot M, Personne P, Gounoue R, et al. Prevalence of and risk factors for anaemia in young children in southern Cameroon. Am J Trop Med Hyg. 1998;58:606-11.

57. Desai MR, Terlouw DJ, Kwena AM, Phillips-Howard PA, Kariuki SK, Wannemuehler KA, et al. Factors associated with hemoglobin concentrations in pre-school children in Western Kenya: Cross-sectional studies. Am J Trop Med Hyg. 2005;72:47-59.

\section{Submit your next manuscript to BioMed Central and we will help you at every step:}

- We accept pre-submission inquiries

- Our selector tool helps you to find the most relevant journal

- We provide round the clock customer support

- Convenient online submission

- Thorough peer review

- Inclusion in PubMed and all major indexing services

- Maximum visibility for your research

Submit your manuscript at www.biomedcentral.com/submit
) Biomed Central 